\title{
E-COMMERCE IMPACT ON ECONOMIC GROWTH
}

\author{
Aleksandar Parishev \\ Faculty of Economics - Skopje, Ss. Cyril and Methodius University \\ aleksandar.parisev@eccf.ukim.edu.mk \\ Goran Hristovski \\ Faculty of Economics - Skopje, Ss. Cyril and Methodius University \\ goran.hristovski@eccf.ukim.edu.mk \\ Petar Jolakoski \\ Faculty of Economics - Skopje, Ss. Cyril and Methodius University \\ jolakoskip@eccf.ukim.edu.mk \\ Viktor Stojkoski \\ Faculty of Economics - Skopje, Ss. Cyril and Methodius University \\ vstojkoski@eccf.ukim.edu.mk
}

\begin{abstract}
Ever since the dawn of merchanting, traders have sought ways to ease the cost of transactions. The recent growth of information and communication technology provided a wide range of solutions for international and national transactions by introducing ecommerce. As a result of this development, e-commerce recently emerged as a dominant transaction activity with a significant impact on the national economies. In recent years the potential of e-commerce has been widely discussed, with a particular focus on its effects on greater economic welfare and prosperity. Yet, despite an abundance of studies that have been done on investigating the role of e-commerce in an economy, a thorough and detailed econometric examination on its impact is still an underexplored avenue. This paper attempts to bridge this gap by investigating the impact of volume of online transactions (e-commerce) and gross capital formation on economic growth, using panel data on 31 European countries covering a 16 years' period. The empirical panel data model is estimated by employing the Generalized Method of Moments. The main findings from the study show that e-commerce and gross capital formation have positive and significant effects on GDP per capita based on purchasing power parity, with e-commerce having a weaker development-enhancing effect in comparison to gross capital formation. In addition, this paper proposes a fruitful discussion on how to provide balance between the growth of e-commerce, the focus on improving other aspects and generating optimal economic welfare and prosperity. Our paper ends with directions for future research.
\end{abstract}

Keywords: E-commerce, Economic growth, Generalized method of moments (GMM)

JEL classification: $047, F 43$, L81

http://doi.org/10.47063/EBTSF.2020.0017

http://hdl.handle.net/20.500.12188/9682 


\section{INTRODUCTION}

Ever since the dawn of merchanting, traders have sought for ways to ease the cost of transactions, (Mankiw, 2014). The recent rise of information and communication technology provided a rapid solution for international, as well as national, transactions by introducing e-commerce. Formally, e-commerce is understood to mean the production, distribution, marketing, or delivery of goods and services by electronic means. An e-commerce transaction can be between enterprises, households, individuals, governments and other public or private organizations (WTO, 1998). In other words, e-commerce is the buying and selling of goods and services, or the transmitting of funds or data, over an electronic network, primarily the internet. As such, this mechanism changed the transactions between businesses, consumers and all the parties included in the process and resulted in the development of new payment methods, enterprise resources planning systems, etc. A growing body of literature indicates that e-commerce has a positive impact on economic growth which describes the increase of efficient production of goods and services in an economy. Hence, it can be conjectured that e-commerce may have an inevitable potential in improving the welfare of a nation.

Motivated by these discussions, here we evaluate the empirical impact of e-commerce on economic growth using panel data on 31 European countries, covering a 16-year period. We provide evidence on the positive impact and quantify the corresponding magnitude. By comparing the estimated regression coefficient with th at of gross investments, we find that e-commerce has 10 times smaller impact. Even though it may be argued that the effect of e-commerce on growth is negligible, we conjecture that this value is further dependent on the level of information and communication usage by a particular country. This leads to a discussion on how to provide balance between the growth of e-commerce, the focus on improving other aspects and generating optimal economic welfare and prosperity.

The rest of the paper is organized as follows. In Section 2 we review the existing literature. In Section 3 we specify our econometric model and describe the data. In Section 4 we provide our empirical results, whereas in Section 5 we discuss relevant implications for achieving optimal growth of e-commerce by giving a simple example for the economy of North Macedonia. In the last section we summarize our findings.

\section{LITERATURE REVIEW}

There is a significant amount of research that has been done on investigating the role of ecommerce in an economy. Here, in short we review this literature.

First, Jo et al. (2019) examined the impact of e-commerce on urban prices and welfare. Their results show that goods sold intensively online had lower relative rates of price increase than goods sold mainly in physical stores. Additionally, their findings suggest that e-commerce has contributed in increasing the gap in inflation rates. Furthermore, their results show that national gains from ecommerce were substantial and the welfare rose much more for residents of high-income cities with highly educated populations and may have fallen for residents of other cities.

In a similar context, Cardona et al. (2015) use a macro-economic general equilibrium model that brings together the impact on consumers as well as on producers. In this study, the authors detected that cross-border e-commerce reduces trade costs compared to offline trade. Subsequent increases in competitive prices squeezes domestic retail price margins and has a negative output effect in that sector (the effect is approximately a decline of $2.6 \%$ ). However, the resulting retail efficiency gains have a positive effect on production in other sectors (between 0.9 and 2.6\%) and on household consumption (1.07\%). The combined macro-economic effect of these transmission channels adds 
$0.14 \%$ to GDP in the European Union. Therefore, the relatively weak GDP effect in comparison with the production and consumption effects indicates that the shift from offline to online retail induces considerable welfare redistribution from retailing to other sectors and to households, more so than a production effect. It is evident that e-commerce has an influential role not only on production and consumption but also on GDP and welfare.

Sumanjeet (2008) aimed to study the economic implications of e-commerce. In his paper, two types of potential economic gains from the use of e-commerce and IT enabled technologies are pointed out. First, there are the gains in efficiency, i.e. efficient use of scarce resources allowing higher consumption in the present and enabling of new digitized goods and services. The second type of potential benefits comes from cost reductions emphasizing search cost, administration cost, distribution cost and even labor costs. Terzi (2011) elaborates on the impact of e-commerce on international trade and employment. Assuming that e-commerce will contribute to increases in volume of international trade. Thus, import open countries will benefit from knowledge spillovers from high-income economies. In addition, creation and job losses are expected to be driven by ecommerce. Xing (2017) examines the impact of internet and e-commerce adoption on bilateral trade flows. The results indicate that better access to the modern ICT and adoption of e-commerce applications stimulate bilateral trade flows at various levels and highlight a great potential of ecommerce for developing and least-developing countries. Conversely to most of the authors, $\mathrm{He}$ and Wang (2019) estimate the relationship between cross-border e-commerce trade (import and export) and macroeconomic indicators like GDP, population, terms of trade and real exchange rate. Operating with dynamic ordinary least squares and error correction model their findings express a long run relationship between the variables and that the GDP and the real exchange rate always affect the development of cross-border e-commerce trade. Georgiou (2009) attempts to inspect the impact of e-commerce on economic growth. It is elaborated that e-commerce has a positive impact on economic growth through promoting consumptions which in turn improves company performance.

Rao et al. (2010) analyze the impact of the development of e-commerce on China's economic growth from an empirical perspective. Using e-commerce transactions and GDP data as well as an error correction model, it was concluded that e-commerce transactions promote economic development. Liu (2013) examines the impact mechanism of e-commerce development to the national economic growth. The used variables were the development of e-commerce in consumption, investment, government purchase and net exports respectively, leading to the conclusion that e-commerce is indeed a promoter of economic growth. Lund and McGuire, (2005) questioned the readiness of developing countries for e- commerce adoption in order to take full advantage of the process actually from the e-commerce benefits in sense of development. Even though exceptions exist, they emphasize the need of government policies improvements especially in the field of infrastructure and human capital, with an aim of better utilization of e-commerce macroeconomic gains. Liu et al. (2013) investigated the impact of e-commerce and research and development (R\&D) on productivity. Using the generalized method of moments technique and unique panel dataset from manufacturing firms, their results showed that both e-commerce and R\&D capital have positive influence on productivity with a complementary relationship between them, on enhancing productivity. At the same time, $R \& D$ exhibits larger productivity-enhancing effects. Similar to them, Anvari and Norouzi (2016) inspected the impact of e-commerce and R\&D on economic development. Working with panel data (purchases by individuals as measure for ecommerce, R\&D expenditure and other variables) and generalized least squares method, they found out that e-commerce and R\&D expenditure have a long run impact with GDP per capita. Actually, both e-commerce and R\&D expenditure have been found to have a positive impact on GDP per 
capita with e-commerce having a stronger development-enhancing effect. Falk and Hagsten (2015) investigated patterns in e-commerce activities and their impact on labor productivity growth. Concretely speaking, their findings showed that one percent point increase in e-sales raises labor productivity growth by 0.3 percent point over two-year period. Also, a larger impact is noticed in the services industries rather than those in manufacturing. Furthermore, their results indicated that smaller firms gain the most from increases in e-sales.

It is evident that e-commerce is influential to many economic aspects, in one way or another, to the overall economic prosperity. This fueled our interest in exploring this impact more deeply, and while doing so, to see if there is a potential for improvement.

\section{EMPIRICAL MODEL AND DATA}

In this section, we adopt an empirical specification that captures the long-run relationship between a set of three variables: income per capita, volume of e-commerce and gross capital formation; and describe the data.

The dependent variable, income, is measured as real GDP per capita corrected for Power Purchasing Parity. Its changes usually represent the economic growth of a country and they can be explained with various factors. However, our main goal is to do it with an indicator of the volume of e-commerce. For that purpose, we follow the existing literature, in particular Anvari and Norouzi (2016), and use the percentage of the total population that made an online purchase as our measure of e-commerce development.

Nevertheless, e-commerce volume alone is not enough to explain economic growth, as it fails to explain various effects. Therefore, we include the Gross Capital Formation as a percent of nominal GDP. This indicator represents a simplification of the investments in the country which have been extensively utilized as a crude approximation for a number of factors that can affect both financial development and economic growth by evolving smoothly over time, see (Herzer and Vollmer, 2012). In the long run this ratio should promote technology indirectly and increase the wealth of a nation, (Levine and Renelt, 1992).

\subsection{Empirical specification}

Many of the endogenous growth proponents, such as Romer (1990), suppose that an economy grows exponentially. We accept their opinion and assume that our basic empirical model is given by:

$$
\mathrm{d} \log \left(g d p_{c t}\right)=\alpha_{c}+\beta_{1} \mathrm{~d} \log \left(e c_{c t}\right)+\beta_{2} \mathrm{~d} \log \left(g c f_{c t}\right)+u_{c t}
$$

where $i=1,2, \ldots, C$ and $t=1,2, \ldots, T$ are country and time notations, $\mathrm{d}$ is the first difference operator, $e c_{c t}$ stands for the percentage of the population that made an online purchase and $g c f_{c t}$ is the Gross Capital Formation as a percent of GDP. The level of economic development is represented by real GDP per capita, $g d p_{c t}$. The $\beta$ coefficients in (1) capture the relationships between the variables, while $\alpha_{c}$ are country specific fixed effects that help to control any omitted factors that are stable over time. We point out that every variable is measured in its logged first differences. This means that we are looking at the growth rates of each variable, thus controlling for possible nonstationarity of the data. 


\subsection{Data and descriptive statistics}

For the purpose of examining the effect of e-commerce over growth we collect annual GDP and gross capital formation data from the World Development Indicators Database. The data for the percentage of the population that made an online purchase is taken from the Eurostat database and has been cross-validated by analyzing the statistical accounts of each country.

We focus on the period from 2004, when most of the sampled countries started reporting the data, until 2018, when was the last time they reported it. In total, we end up with an unbalanced panel of 417 observations, covering 31 European countries. The panel is unbalanced because in some years some country data was missing. We choose this period as it produces the largest relevant dataset for Europe, which can be used for investigating the impact of e-commerce on economic growth. The countries included in the sample represent a heterogeneous group of economies, i.e. the sample includes both developed and developing countries and thus it provides a representative picture for the global behavior. We opt to use online purchases by individuals, as it offers detailed information for the activity of the users of e-commerce within the population and as such, it is a suitable approximation for the level of development of the e-commerce industry in the economy.

Table in Appendix gives the country summary statistics. The statistics reveal that the selected countries exhibit great disparities in the magnitude of the studied variables. Between the cross sections, Sweden has the highest average percentage of online purchases, followed by Finland, Iceland and Netherlands, while North Macedonia has the lowest average percentage. This can be assumed as an indicator that Macedonian e-commerce is at its early stages of development.

Average per-capita GDP is highest in Norway, followed by Netherlands and Denmark. North Macedonia is the poorest country in the sample. The summary statistics suggest that, overall, the percentage of online purchases, the Gross Capital Formation to GDP and the income per capita have grown constantly through the years, with more developed countries (in terms of GDP) exhibiting faster e-commerce volume growth.

\section{EMPIRICAL ANALYSIS}

\subsection{Stationarity test}

Prior to conducting an empirical panel regression estimation, all variables should be stationary. This is formally tested by examining the unit roots of the variables. Since the data we gathered is unbalanced, a convenient test is the Fischer-type Phillips-Perron test (Phillips and Perron, 1988). Under this test the null hypothesis states that all panels contain unit root, and the statistic follows an inverse Chi-squared distribution.

The unit root statistics for each of the variables is given in Table 1. We observe that the null hypothesis is rejected for every variable at the $1 \%$ level, thus suggesting that all of them are stationary and convenient for modeling.

Table 1: Panel Unit Root Test statistics

\begin{tabular}{|c|c|}
\hline Variable & PP-Statistics \\
\hline $\operatorname{dlog}\left(g d p_{c t}\right)$ & $152.63^{*}$ \\
\hline $\operatorname{dlog}\left(g c f_{c t}\right)$ & $266.49^{*}$ \\
\hline $\operatorname{dlog}\left(e c_{c t}\right)$ & $687.14^{*}$ \\
\hline
\end{tabular}

Notes: One lag were selected to adjust for autocorrelation. Individual intercepts were included in every test. "Indicates significance at $1 \%$ level.

Source: Authors' compilation 


\subsection{Model estimation}

Since the pre-test for unit-roots suggests that the data is suitable for evaluating the relationship between growth, investments and e-commerce volume we proceed with estimation of the model. In general, the relationship between the studied variables may be endogenous, i.e. e-commerce may drive the economic growth, but also the economic growth of the country may improve the level of e-commerce development. As a way to deal with this problem, we opt for a generalized method of moments estimation. This procedure yields consistent, asymptotically normal, and efficient estimates, even if there are endogenous regressors, thus allowing us to control for the potential endogeneity in the relationships of our variables of choice. Table 2 provides the estimates of our model.

Table 2: GMM estimates of relationship

\begin{tabular}{|c|c|c|}
\hline \multicolumn{3}{|c|}{ Dependent variable: $\operatorname{dlog}\left(\mathrm{gdp}_{\mathrm{ct}}\right)$} \\
\hline Variable & Coefficient & Standard Error \\
\hline $\operatorname{dlog}\left(e c_{c t}\right)$ & $0.02^{*}$ & 0.00 \\
\hline $\operatorname{dlog}\left(g c f_{c t}\right)$ & $0.22^{*}$ & 0.02 \\
\hline
\end{tabular}

Notes: Lagged values of the independent variables were used as instruments. "Indicates significance at $1 \%$ level.

Source: Authors' compilation

The results suggest that both investments and development of e-commerce have a significant and positive impact on economic growth. A positive change of one percentage point in the growth rate of gross capital formation is associated with an increase in the growth rate of GDP by 0.22 percentage points. Similarly, a change of one percentage points in the volume of e-commerce leads to an increase in the economic growth of 0.02 percentage points. The magnitude of the effect of volume of ecommerce is more than 10 times smaller than the gross effect investments. On the first sight, this may suggest that the impact of e-commerce is negligible. Nevertheless, we point out that given the fact that e-commerce trade is based on new technologies whose full potential is yet to be explored, the observed effect is already larger than one should initially expect. We believe that a more detailed approach which captures the extent of e-commerce development will elucidate the differences in the magnitude of the coefficient between countries whose usage of information and communication technologies is by far more pronounced. However, such study is out of the domain of the current paper and we leave it for future work.

\section{DISCUSSION}

As we observed from the literature review and this research, there is an abundance of empirical evidence which suggests that e-commerce and its development may have a positive impact on the economic growth of a country. This should be especially true in developed countries, which due to more favorable conditions had the opportunity to invest earlier in the development of this trade. Our sample included both developed and developing countries and, thus, we can conjecture that ecommerce development is also of immense importance in less developed economies.

To this end, here we comment on a few possible suggestions that, in our modest view, would be appropriate for how a developing country, should streamline their development strategies in order to maximize the benefits from e-commerce. Specifically, we believe that governments should:

Invest in ICT infrastructure; 
This can be done with telecom liberalization, which will make the telecommunications market more competitive and, in turn, lead to lower prices and better quality services for consumers. As a result it would increase the overall quality of the infrastructure in terms of speed, reliability and of course usage. Regarding e-commerce this means that the greater part of the population will have the potential to become a participant in such transactions.

Opt in digitization of society;

The services provided by the government to the businesses and consumers need to be in electronic form and preferred. This will encourage users to participate in electronic transactions more frequently, depending on their needs. It can also contribute to increased confidence in established systems.

Invest in human capital;

Investments in human capital are needed to develop e-commerce. Specifically, it is necessary to invest in knowledge that can contribute in many ways. One aspect is the creation of a skilled workforce, which is important when creating any form of electronic infrastructure. Another aspect is the reduction of the digital illiteracy of the population, which is considered a barrier of ecommerce development. Such measures can greatly contribute to accelerated development.

Protect trade participants;

Protection involves the creation of mechanisms and legal frameworks that allow for increased security, privacy, protection of intellectual property rights and so on; for each of the participants. In fact, it is necessary to advance the relevant laws and regulations to create a good e-market. This is a key element, from the very existence of e-commerce to the present day.

Set e-commerce entrepreneurship as a national priority;

Promoting entrepreneurship in e-commerce should be a priority. This is supported by the fact that most of the volume of trade belongs to transactions between businesses. Some of the measures that can be mentioned to encourage entrepreneurship are tax exemptions for all those who want to create their own online business. Innovative entrepreneur approach, access to global markets followed by lower costs will for sure boost the national economy.

To summarize, it is required governments to adopt macroeconomic policies that will continuously provide a favorable economic environment for the sound development of electronic commerce. It is important to emphasize that we believe that our suggestions will exhibit distinct importance depending on the economy under question, given the fact that the level of development of ecommerce is also different.

\section{CONCLUSION}

Research on technological changes, their significance and impact, are constantly rising. The purpose of this research was to investigate the effect of a particular technological change, the introduction of e-commerce, and how its development affects economic growth. In addition, it attempts to determine the intensity of the impact of e-commerce development compared to the Gross Capital Formation, which is predicted to have an influence on growth. The need for this research stems from the accelerated advances in technology as well as the global increase in the volume of e-commerce. According to the results, which showed a strong relationship between the used variables, we can conclude that electronic commerce contributes to the growth and development of national economies. This finding is supported by empirical research that included macroeconomic aspects through Gross Domestic Product (GDP) and Gross Capital Formation (GCF), as well as an indicator of the development of e-commerce in selected countries through online purchases by individuals. The results indicate the importance of the role e-commerce has, 
as measured, in the economic growth and development of a country. They are in line with existing literature on the chosen topic, in which we find the contribution not only to reaffirm the impact of e-commerce, but also to demonstrate its importance. We believe that this encourages further scientific research to be focused on finding ways to maximize its benefits.

It is important to note that this research may be perceived as being limited mainly because of short time series, as is the case with some other studies, but nevertheless it still produces relevant implications. Another limitation of our study is that we focus on the level of e-commerce development within a country, and an enterprise specific analysis is not taken into account here. This is a consequence of the lack of data on selected countries, which have a significant share in the volume of e-commerce. In this aspect, we believe that an analysis which incorporates micro level data is a fruitful subject for further expansion of this research. Finally, we point out that it would be much more appropriate to analyze the impact and dependencies if there is a generally accepted e-commerce index, which is not the case yet. In this aspect, our measure should only represent a part of this index.

We conclude by re-stating our initial hypothesis that e-commerce has an impact on economies and its scope and influence are growing. Therefore, it is necessary to think in the direction of making the best use of its potential. In this sense, it is desirable for countries to adopt policies that will contribute to a more stable and greater development of e-commerce and thus to the national economy. This is especially true for developing countries where the e-commerce technology is still in its infancy, such as the Republic of North Macedonia. In this country, the low level of ecommerce is a result of several factors such as low level of financial literacy, distrust in the banking system, aversion to innovation in traditional ways of trading, high degree of informal economy, etc. We argue that the most appropriate measures to encourage the implementation of e-commerce in North Macedonia is to follow our policy recommendations, described in the Discussion section and improve the digitalisation of society, the protection of trade participants and the establishment of entrepreneurship in e-commerce as a national priority.

\section{REFERENCES}

Anvari, R.D. and Norouzi, D. (2016), "The impact of e-commerce and R\&D on economic development in some selected countries", Procedia-Social and Behavioral Sciences, Vol. 229, pp. 354-362.

Cardona, M., Duch-Brown, N., Francois, J., Martens, B. and Yang, F. (2015), "The macroeconomic impact of e-commerce in the EU digital single", working paper [No. 2015/09]., Institute for Prospective Technological Studies Digital Economy.

Falk, M. and Hagsten, E. (2015), "E-commerce trends and impacts across Europe". International Journal of Production Economics, Vol. 170, pp. 357-369.

Georgiou, M.N. (2009), "E-commerce has a positive impact on economic growth: A panel data analysis for Western Europe", available at SSRN 1484687.

Herzer, D. and Vollmer, S. (2012), "Inequality and growth: evidence from panel cointegration", The Journal of Economic Inequality, Vol. 10 No. 4, pp. 489-503.

He, Y. and Wang, J. (2019), "A Panel Analysis on the Cross Border E-commerce Trade: Evidence from ASEAN Countries", The Journal of Asian Finance, Economics and Business, Vol. 6 No. 2, pp. 95-104.

Jo, Y.J., Matsumura, M. and Weinstein, D.E. (2019), "The Impact of E-Commerce on Urban Prices and Welfare", working paper [No. 26506], National Bureau of Economic Research, November. 
Levine, R. and Renelt, D. (1992), "A sensitivity analysis of cross-country growth regressions", The American economic review, Vol. 82, No. 4, pp. 942-963.

Liu, T.K., Chen, J.R., Huang, C.C. and Yang, C.H. (2013), "E-commerce, R\&D, and productivity: Firm-level evidence from Taiwan", Information Economics and Policy, Vol. 25 No. 4, pp. 272283.

Liu, S. (2013), "An Empirical Study on E-commerce's effects on Economic Growth", in 2013 Conference on Education Technology and Management Science (ICETMS 2013). Atlantis Press.

Lund, M.J. and McGuire, S. (2005), "Institutions and development: Electronic commerce and economic growth", Organization Studies, Vol. 26 No.12, pp. 1743-1763.

Mankiw, N.G. (2014), Macroeconomía. Antoni Bosch Editor.

Phillips, P.C. and Perron, P. (1988), "Testing for a unit root in time series regression", Biometrika, Vol. 75 No. 2, pp. 335-346.

Rao, Y., Zhang, K. and Li, L. (2010), "The Econometric Analysis of the Relationship between Chinese e-Commerce Transactions and GDP", in 2010 International Conference on Management of e-Commerce and e-Government, IEEE, pp. 248-251.

Romer, P.M. (1990), "Endogenous technological change", Journal of political Economy, Vol. 98 No.5, Part 2, pp. S71-S102.

Sumanjeet, S. (2008). "Impact of e-commerce on economic models: little to lose; more to gain", International Journal of Trade and Global Markets, Vol. 1 No. 3, pp. 319-337.

Terzi, N. (2011), "The impact of e-commerce on international trade and employment", Procediasocial and behavioral sciences, Vol. 24, pp. 745-753.

Xing, Z. (2018), "The impacts of Information and Communications Technology (ICT) and Ecommerce on bilateral trade flows", International Economics and Economic Policy, Vol. 15 No. 3, pp. 565-586.

World Trade Organization, (1998), "Work programme on electronic commerce", WT/L/274. WTO, Geneva, 30 September.

\section{APPENDIX}

Table: Summary Statistics

\begin{tabular}{|l|l|r|r|r|}
\hline Country & Statistic & \multicolumn{1}{l|}{ gdp } & \multicolumn{1}{l|}{ gcf } & ec \\
\hline Austria & Obs. & 15,00 & 15,00 & 15,00 \\
\hline & Mean & 43791,49 & 23,94 & 48,00 \\
\hline & Std. Dev. & 1484,78 & 0,67 & 12,72 \\
\hline Belgium & Obs. & 14,00 & 14,00 & 14,00 \\
\hline & Mean & 41315,61 & 23,91 & 40,00 \\
\hline & Std. Dev. & 1166,85 & 1,04 & 13,72 \\
\hline Bulgaria & Obs. & 13,00 & 13,00 & 13,00 \\
\hline & Mean & 16152,18 & 24,81 & 15,23 \\
\hline & Std. Dev. & 1660,96 & 5,92 & 8,53 \\
\hline Croatia & Obs. & 12,00 & 12,00 & 12,00 \\
\hline & Mean & 21483,63 & 22,59 & 25,58 \\
\hline & Std. Dev. & 1142,56 & 3,94 & 11,88 \\
\hline Cyprus & Obs. & 14,00 & 14,00 & 14,00 \\
\hline & Mean & 32947,33 & 20,05 & 20,64 \\
\hline
\end{tabular}




\begin{tabular}{|c|c|c|c|c|}
\hline & Std. Dev. & 1933,01 & 4,98 & 9,55 \\
\hline \multirow[t]{3}{*}{ Czechia } & Obs. & 15,00 & 15,00 & 15,00 \\
\hline & Mean & 28972,87 & 27,66 & 34,60 \\
\hline & Std. Dev. & 2365,60 & 2,18 & 18,02 \\
\hline \multirow[t]{3}{*}{ Denmark } & Obs. & 15,00 & 15,00 & 15,00 \\
\hline & Mean & 45403,30 & 21,35 & 73,40 \\
\hline & Std. Dev. & 1477,95 & 2,14 & 11,80 \\
\hline \multirow[t]{3}{*}{ Estonia } & Obs. & 13,00 & 13,00 & 13,00 \\
\hline & Mean & 26446,95 & 28,11 & 35,00 \\
\hline & Std. Dev. & 2419,47 & 5,93 & 21,15 \\
\hline \multirow[t]{3}{*}{ Finland } & Obs. & 15,00 & 15,00 & 15,00 \\
\hline & Mean & 40358,53 & 23,42 & 63,67 \\
\hline & Std. Dev. & 1337,12 & 1,33 & 13,32 \\
\hline \multirow[t]{3}{*}{ France } & Obs. & 13,00 & 13,00 & 13,00 \\
\hline & Mean & 37659,64 & 22,91 & 56,15 \\
\hline & Std. Dev. & 852,82 & 0,81 & 13,55 \\
\hline \multirow[t]{3}{*}{ Germany } & Obs. & 15,00 & 15,00 & 15,00 \\
\hline & Mean & 41641,38 & 20,39 & 62,27 \\
\hline & Std. Dev. & 2784,35 & 0,89 & 12,78 \\
\hline \multirow[t]{3}{*}{ Greece } & Obs. & 13,00 & 13,00 & 13,00 \\
\hline & Mean & 27812,80 & 18,07 & 20,15 \\
\hline & Std. Dev. & 3163,18 & 6,23 & 13,75 \\
\hline \multirow[t]{3}{*}{ Hungary } & Obs. & 15,00 & 15,00 & 15,00 \\
\hline & Mean & 23920,01 & 23,10 & 26,67 \\
\hline & Std. Dev. & 1937,06 & 2,55 & 12,71 \\
\hline \multirow[t]{3}{*}{ Iceland } & Obs. & 6,00 & 6,00 & 6,00 \\
\hline & Mean & 43905,96 & 18,17 & 63,67 \\
\hline & Std. Dev. & 3436,53 & 3,33 & 11,52 \\
\hline \multirow[t]{3}{*}{ Ireland } & Obs. & 14,00 & 14,00 & 14,00 \\
\hline & Mean & 51914,83 & 25,15 & 50,07 \\
\hline & Std. Dev. & 8940,64 & 6,42 & 11,84 \\
\hline \multirow[t]{3}{*}{ Italy } & Obs. & 14,00 & 14,00 & 14,00 \\
\hline & Mean & 36148,99 & 19,29 & 19,64 \\
\hline & Std. Dev. & 1559,12 & 2,02 & 9,26 \\
\hline \multirow[t]{3}{*}{ Latvia } & Obs. & 15,00 & 15,00 & 15,00 \\
\hline & Mean & 21068,55 & 27,56 & 28,27 \\
\hline & Std. Dev. & 2830,92 & 7,13 & 15,35 \\
\hline \multirow[t]{3}{*}{ Lithuania } & Obs. & 15,00 & 15,00 & 15,00 \\
\hline & Mean & 23832,42 & 21,60 & 22,87 \\
\hline & Std. Dev. & 4094,95 & 4,69 & 16,02 \\
\hline \multirow{3}{*}{$\begin{array}{l}\text { Luxembou } \\
\text { rg }\end{array}$} & Obs. & 15,00 & 15,00 & 15,00 \\
\hline & Mean & 92565,99 & 19,06 & 60,47 \\
\hline & Std. Dev. & 3253,99 & 1,24 & 17,52 \\
\hline Malta & Obs. & 14,00 & 14,00 & 14,00 \\
\hline
\end{tabular}




\begin{tabular}{|c|c|c|c|c|}
\hline & Mean & 30759,38 & 20,80 & 38,93 \\
\hline & Std. Dev. & 4079,71 & 2,19 & 12,37 \\
\hline \multirow{3}{*}{$\begin{array}{l}\text { Netherland } \\
\mathrm{s}\end{array}$} & Obs. & 15,00 & 15,00 & 15,00 \\
\hline & Mean & 46423,07 & 20,52 & 63,60 \\
\hline & Std. Dev. & 1723,04 & 1,46 & 14,70 \\
\hline \multirow{3}{*}{$\begin{array}{l}\text { North } \\
\text { Macedonia }\end{array}$} & Obs. & 13,00 & 13,00 & 13,00 \\
\hline & Mean & 11812,51 & 28,24 & 8,79 \\
\hline & Std. Dev. & 1102,11 & 3,68 & 8,85 \\
\hline \multirow[t]{3}{*}{ Norway } & Obs. & 15,00 & 15,00 & 15,00 \\
\hline & Mean & 63478,52 & 26,06 & 73,87 \\
\hline & Std. Dev. & 1165,26 & 1,99 & 8,97 \\
\hline \multirow[t]{3}{*}{ Poland } & Obs. & 15,00 & 15,00 & 15,00 \\
\hline & Mean & 22419,39 & 21,13 & 34,60 \\
\hline & Std. Dev. & 3645,09 & 1,77 & 14,86 \\
\hline \multirow[t]{3}{*}{ Portugal } & Obs. & 15,00 & 15,00 & 15,00 \\
\hline & Mean & 26964,57 & 19,34 & 22,93 \\
\hline & Std. Dev. & 898,13 & 3,48 & 11,81 \\
\hline \multirow[t]{3}{*}{ Romania } & Obs. & 13,00 & 13,00 & 13,00 \\
\hline & Mean & 19450,41 & 26,74 & 11,92 \\
\hline & Std. Dev. & 2561,37 & 2,91 & 7,72 \\
\hline \multirow[t]{3}{*}{ Slovakia } & Obs. & 15,00 & 15,00 & 15,00 \\
\hline & Mean & 25680,73 & 24,55 & 40,53 \\
\hline & Std. Dev. & 3540,79 & 3,09 & 19,40 \\
\hline \multirow[t]{3}{*}{ Slovenia } & Obs. & 13,00 & 13,00 & 13,00 \\
\hline & Mean & 29489,25 & 23,09 & 35,77 \\
\hline & Std. Dev. & 1493,20 & 5,36 & 11,99 \\
\hline \multirow[t]{3}{*}{ Spain } & Obs. & 15,00 & 15,00 & 15,00 \\
\hline & Mean & 32673,16 & 22,96 & 32,60 \\
\hline & Std. Dev. & 1283,54 & 5,01 & 14,65 \\
\hline \multirow[t]{3}{*}{ Sweden } & Obs. & 15,00 & 15,00 & 15,00 \\
\hline & Mean & 44112,52 & 23,86 & 70,40 \\
\hline & Std. Dev. & 2226,90 & 1,48 & 9,97 \\
\hline \multirow{3}{*}{$\begin{array}{l}\text { United } \\
\text { Kingdom }\end{array}$} & Obs. & 14,00 & 14,00 & 14,00 \\
\hline & Mean & 38081,29 & 17,00 & 63,64 \\
\hline & Std. Dev. & 1181,10 & 1,05 & 15,72 \\
\hline
\end{tabular}

